\title{
Medyada Yer Alan Kanser Haberlerinin Değerlendirilmesi
}

\author{
Evaluation of Cancer News in the Media \\ Gürkan Muratdağ1 ${ }^{1}$, Neșe Aşı1ci², Gökhan Oturak², Fulya Aktan Kibar² ${ }^{2}$ Mine Keskin², \\ Ufuk Berberoğlu ${ }^{3}$, Hasan Çetin Ekerbiçer ${ }^{2}$, Abdülkadir Aydın ${ }^{1}$ \\ ${ }^{1}$ Sakarya Üniversitesi Tip Fakültesi, Aile Hekimliği A.D, Sakarya \\ ${ }^{2}$ Sakarya Üniversitesi Tip Fakültesi, Halk Sağlı̆̆ A.D, Sakarya \\ ${ }^{3}$ Uşak üniversitesi Tip Fakültesi, Halk Sağlı̆̆ı A.D, Uşak \\ Yazı̧̧a Adresi / Correspondence: \\ Gürkan Muratdağ1 \\ Sakarya Üniversitesi Tip Fakültesi, Aile Hekimliği A.D, Sakarya \\ T: +905330946333 E-mail : drgm54@gmail.com \\ Geliş Tarihi / Received : 12.05.2019 Kabul Tarihi / Accepted : 12.10.2019 \\ Orcid : \\ Gürkan Muratdağı https://orcid.org/: 0000-0002-9629-3973 \\ Neşe Aircı https://orcid.org/: 0000-0003-0266-6845 \\ Gökhan Oturak https://orcid.org/0000-0003-1608-8433 \\ Fulya Aktan Kibar https://orcid.org/: 0000-0003-3080-4280 \\ Mine Keskin https://orcid.org/: 0000-0003-2387-7473 \\ Ufuk Berberoğlu https://orcid.org/0000-0002-4088-7289 \\ Hasan Çetin Ekerbiçer https://orcid.org/0000-0003-0064-3893 \\ Abdülkadir Aydın https://orcid.org/0000-0003-0663-586X
}

( Sakarya Tip Dergisi / Sakarya Med J 2019, 9(4):619-625) DOI: 10.31832/smj.562475

Öz

Amaç Kanser gibi mortalitesi yüksek hastalıklarda farkındalığı artırabilmek ve bu sayede erken tanı ve tedavi olanaklarını yakalayabilmek önemlidir. Medya da bu konuda önemli bir rol oynar. Bu çalışmada medyadaki kanser haberlerinin içeriklerini ve topluma verdikleri mesajların kanıta dayalı tıp yönünden doğruluk ve güvenilirliklerini araștırmak amaçlanmıștır.

Gereç ve Kesitsel tipte tanımlayıcı olarak tasarlanan bu çalısma için Kasım 2018 ile Aralık 2018 tarihleri arasındaki bir aylık dönemde en çok ziyaret edilen beș gazetenin web Yöntemler sayfası ile beş haber sitesindeki kanser haberleri geriye dönük olarak incelenmiştir. İncelenen haberlerden aynı içeriğe sahip olanlardan yalnızca biri seçilerek, toplam 459 tekil (bağımsız) haber çalıșmaya dahil edilmiștir. Haberler, içeriklerine, kanser türlerine, haber kaynaklarına, haber ile başlık uyumuna ve kanıt düzeylerine göre değerlendirilmiştir. Verilerin tanımlayıcı istatistikleri, SPSS 21 programı kullanılarak sayı ve yüzde şeklinde ifade edilmiştir.

Bulgular İncelenen toplam 459 tekil habere bakıldığında, \% 26’sı magazinsel haberler, \%23’ü önleme ve korunma ile ilgili öneriler ve \% 15’i kanser tanısı haberlerinden olusmaktadır. Haberlerin \%48'i genel olarak kanser hastalığı hakkında yapılmış olup, \%7,1'inde meme kanseri, \%6,8'inde ise akciğer kanseri konu alınmıștır. Haberlerin tümünde, başlıkiçerik uyumunun $\% 94$, literatür taraması sonucunda kanıta dayalı tıp ile uyumluluğunun ise $\% 45$ sıklıkta olduğu belirlenmiştir.

Sonuç Kanser gibi hastalıklarda erken tanı ve tedavi açısından toplumun bilinçlenmesi önem taşımaktadır. Bu konuda internet medyasının gücünün de aktif olarak kullanılması akılcı bir yaklașımdır. Ancak bu gücü doğru kullanabilmek için haberin belli kurallar çerçevesinde ve doğru bilgi içerecek șekilde halka iletilmesi gerekmektedir.

Anahtar Kanser; İnternet; Medya; Analiz

kelimeler

Abstract

Objective It is important to provide early diagnosis and treatment opportunities by raising awareness in high mortality diseases such as cancer. The media also plays an important role in this issue. In this study, it is aimed to investigate the content of cancer news and the accuracy and reliability of cancer messages given to public in terms of evidence-based medicine in the media.

Materials In this cross-sectional descriptive study, cancer reports in the five most visited newspapers and five news sites were reviewed retrospectively in a month between November 2018 and December and Methods 2018. A total of 459 singular (independent) news items were included in the study by selecting only one of the articles with the same content. The news were evaluated according to their content types of cancer, news sources, headline compliance with the news and level of evidence. Descriptive statistics of the data were expressed as numbers and percentages by using SPSS 21 program.

Results In the total of 459 singular news articles, $26 \%$ were magazine news, $23 \%$ were recommendations for prevention and $15 \%$ were cancer news. The types of cancer in the news were classified as; $48 \%$ were general cancer, $7.1 \%$ were breast cancer and $6.8 \%$ were lung cancer. In all the news, the headline-content compliance was $94 \%$ and the literature-based compliance was found to $b e 45 \%$

Conclusion Awareness of the society is important for early diagnosis and treatment of diseases such as cancer. In this regard, it is a rational approach to use the power of internet media, actively. However, in order to use this power correctly, the news must be communicated to the public in accordance with certain rules and with the correct information.

Key words Cancer; Internet; Media; Analysis 


\section{GIIRIŞ}

Medya, haber değeri taşıyan konuları tanımlayıp işleyerek ve bunları pekiştirerek kamu gündemini ve toplumda sağlığa verecekleri öncelikleri belirlemeye yardımcı olabilir. Hastalıklar veya sağlıklı yaşama önerilerini içeren çok sayıda haber toplumun ilgisini çeken ve gündemde olan konu başlıklarıdır. Kişiler, bu haberlerde yer alan önerileri ve uygulamaları hayatlarına uyarlayabilirler. Okuyucular haberlerde yer alan mesajlara sağlık hizmeti sunucularına güvendikleri kadar güvenebilmektedirler. ${ }^{1}$ Özellikle gazeteler ve haber siteleri televizyon ve radyo haberlerine göre bilginin ve iletilmek istenen mesajın aktarılmasında daha başarılıdırlar. Televizyon ve radyolar, haberin kısa sürede ve tekrar geri dönüp incelenme hareketine imkan sağlamamaları nedeniyle, gazeteler kadar konunun içeriğini derinlemesine değerlendirme olanağına sahip değillerdir. ${ }^{2}$

Bilindiği üzere, kanser gibi toplum sağlığg açısından önemli yeri olan hastalıklar konusunda toplumda oluşturulabilecek bir farkındalık, bu tür hastaların erken tanı ve tedavi fırsatını yakalayabilmelerine imkan sağlayacaktır. $\mathrm{Bu}$ konuda gazeteler önemli bir aracı olabilirler. Kamu gündemi kişilerin bu farkındalıkları doğrultusunda şekillenebilmektedir. ${ }^{3}$ Bununla birlikte gazetelerdeki haberlerin reyting kaygıları nedeniyle yanlış ya da eksik içerikleri, toplumun sağlık alanında olumsuz yönlendirilmesine de sebep olabilmektedir. İnsanlar bu yanlış bilgilendirme nedeniyle yanlış davranış kalıpları geliştirebilmektedirler. Bu bağlamda sağlık sunucuları tarafından kanıta dayalı ve bilimsel uygulamaların hayata geçirilmesi sırasında zorluklar çekilebilmekte ve doğru tıbbi müdahaleler kısıtlı ya da uygulanamaz hale dönüşebilmektedir. ${ }^{4}$

2017 yılı Türkiye İstatistik Kurumu verilerine göre Türkiye’deki ölüm nedenleri arasında kansere bağlı ölümler ikinci sıradadır. ${ }^{5} 2015$ yılı verilerine göre ise tüm yaş gruplarındaki erkeklerde en sık görülen ilk beş kanser türü sırasıyla: akciğer, prostat, kolorektal, mesane ve mide kanseri iken kadınlarda: meme, tiroid, kolorektal, uterus korpusu ve akciğer kanseridir. 0-14 yaş arasındaki çocuklarda görülen ilk beş kanser de sırasıyla: lösemi; santral sinir sistemi tümörleri, lenfoma, nöroblastoma ve yumuşak doku sarkomlarıdır. ${ }^{6}$ Kronik ve ölümcül hastalıkların başında yer alan kanser hastalığ 1 konusunda sağlık hizmeti sunanların kamu spotları aracılığı ile ya da kanserle mücadele içerikli halk eğitim programlarıyla insanlara kanser konusunda farkındalık oluşturma görevleri uzun zamandır süregelmektedir. Medyanın yaklaşımı ise doğası gereği ticari kaygıları da (tiraj, reyting, tıklanma sayısı, vb.) içermektedir. Bu kaygılar haberin başlığını, sunum biçimini ve içeriğini olumlu veya olumsuz olarak etkileyebilmektedir. Kimi haberler tümüyle bilimsel kanıtlarla çelişebilmektedir.

Yazılı ya da görsel medyada kanser konusunda çıkan haberlerin içeriklerinin araştırılmasıyla, toplumun kanser konusunda hangi bilgilere ulaştıkları ve ne tür farkındalıklara sahip olacakları da belirlenmiş olacaktır. Bu alanda yapılmış çalışmalar belirli tarih aralıklarında çıkan kanser haberlerinin kanserin hangi tür yönlerini ele aldıklarını veya kanser hakkında topluma bilgi aktarıp aktarmadıklarını incelemek yönünde olmuştur. ${ }^{7,8} \mathrm{Bu}$ çalışmalarda haberlerin bilimsel uygunlukları değerlendirilmemiştir. Yaptığımız çalışmanın amacı yüksek tirajlı gazete ve haber sitelerinde yayınlanan kanser konulu haberlerin içeriklerini ve kaynaklarını kanıta dayalı tıp yönünden inceleyerek doğruluk ve güvenilirliklerini değerlendirmektir.

\section{GEREÇ ve YÖNTEM}

Kesitsel tipte tanımlayıcı olarak tasarlanan bu çalışma için Kasım 2018 ile Aralık 2018 tarihleri arasındaki bir aylık dönemde en çok ziyaret edilen beş gazetenin web sayfası ile beş haber sitesindeki kanser haberleri geriye dönük olarak incelenmiştir. İnternet ortamında en çok tıklanan gazete ve haber yayın organlarının seçimi için www.alexa. com sitesinden "Türkçe Basın ve Yayın” kategorisinden "Gazeteler" ve "Haberler" alt başlıklarına bakılmıştır. Bakılan tarihte en çok tıklanan ilk beş gazete Hürriyet, Milliyet, Sözcü, Sabah ve Posta; ilk beş haber sitesi www.haberturk.com, www.ensonhaber.com, www.haber7.com, www. ntv.com ve www.haberler.com olarak görülmüștür. "Goog- 
le Gelişmiş Arama" seçeneği kullanılarak belirlenen gazete ve haber sitelerinde, Kasım 2018 ile Aralık 2018 tarihleri arasında içinde "kanser" kelimesi geçen tüm haberler incelenmiştir. İncelenen haberlerden aynı içeriğe sahip olanlardan yalnızca biri seçilerek, toplam 459 tekil (bağımsız) kanser haberi çalışmaya dahil edilmiştir.

Bağımsız değişkenler haberin türü, haberin kaynağı, kanserin türü, haberin içeriği ile başlı uyumu ve haberin kanit durumu olarak belirlenmiştir. Haber türü; kanserin etiyolojisi, tanısı, tedavisi, kanserden korunma yöntemleri, kanserin tanımlayıcı epidemiyolojisi, patofizyolojisi ve magazinsel haberler (üçüncü sayfa haberleri, ünlülerin kanser haberleri, sosyal sorumluluk projeleri vb.) olarak sınıflandırılmıştır. Haberin kaynağı, kaynak belirtilip belirtilmemesine göre ikiye ayrılmıştır. Kaynak belirtilen haberlerde haberin kaynağı; Türk tıp doktoru, yabancı tıp doktoru, diyetisyen, tıp dışı Türk bilim insanı, tıp dışı yabancı bilim insanı, tıp kökenli Türk sağlık kuruluşu, tıp kökenli yabancı sağlık kurum/kuruluşu, tıp dışı Türk kurum/kuruluşu, tıp dışı yabancı kurum ve tıp dergisi olarak kategorilere ayrılmıştır. Kanser türleri; genel (özellikle bir kanser türünün belirtilmediği), meme kanseri, akciğer kanseri, kolon kanseri, jinekolojik kanserler, hematolojik maligniteler, prostat kanseri, baş-boyun kanserleri, mide kanseri, mesane kanseri, karaciğer kanseri, kemik tümörleri, tiroid kanseri, böbrek kanseri, özofagus kanseri, pankreas kanseri, deri kanseri, santral sinir sistemi maligniteleri, testis tümörü, yumuşak doku kanseri, metastatik kanserler şeklinde gruplandırılmıştır.

Haberin kanıt durumu; magazinsel haberler dışındaki haber türleri için incelenmiştir ve haberin içeriğindeki bilgiler veya veriler Uptodate, Dynamed, Dünya Sağlık Örgütü (DSÖ) ve Türkiye İstatistik Kurumu (TÜİK) veri tabanlarında yer alıyorsa "Kanıt var", aksi taktirde "Kanıt yok" şeklinde değerlendirilmiştir.

Veriler SPSS 21 (Statistical Package for the Social Sciences) programı kullanılarak değerlendirilmiştir. Tanımlayı- c1 istatistikler sayı (n) ve yüzde (\%) olarak verilmiştir.

\section{BULGULAR}

Beş gazetenin web sayfası ile beş haber sitesi dahil olmak üzere toplam on internet sitesinde, incelenen bir aylık dönemde, tekrarlayan haberler çıartıldıktan sonra tekil (bağımsız) toplam 459 kanser haberine ulaşılmıştır.

Kanser haberlerinin içeriklerine göre dağılımları incelendiğinde; aynı haber içinde birden çok haber türü olabildiğinden toplam 850 haber türü üzerinden değerlendirme yapıldı. Kanser haberleri arasında haber türü açısından ilk sirada magazinsel haberler ( $\mathrm{n}=220, \% 25,88$ ), ikinci sırada ise kanseri önlemeye ve korunmaya yönelik öneriler üzerine yapılmış haberler $(\mathrm{n}=198, \% 23,29)$ yer almaktaydı. (Tablo 1)

Kanser haberlerindeki kanser türlerinin dağılımı incelendiğinde, bir haberde birden çok kanser türü olabildiğinden toplam 531 kanser türü üzerinden değerlendirme yapılmıştır. Haberlerin içeriğindeki kanser türleri incelendiğinde ilk sırada türü belirtilmemiş kanser haberleri $(\%$ 47,85) yer almaktaydı. Türü belirtilen kanser türleri içinde ilk üç sırada, meme kanseri $(\% 7,18)$, akciğer kanseri $(\% 6,78)$ ve kolon kanserinin $(\%$ 6,78) olduğu görülmüştür. (Tablo 2)

İncelenen 459 haberin 182'sinde (\% 36,55) herhangi bir kaynak belirtilmemişken; 277'sinde (\% 63,45) kaynak belirtildiği saptanmıştır. Kaynak belirtilen haberlerin bir kısmında birden çok kaynak belirtildiğinden toplam 316 haber kaynağı üzerinden değerlendirme yapılmıștır. Kaynak belirtilen haberlerde en sik kaynak olarak Türk tip doktorlarının ( $\mathrm{n}=151, \%$ 47,78) gösterildiği gözlenmiştir. (Tablo 3)

Kanser haberlerinin içeriğinin, haber başlığı ile uyum durumu incelendiğinde toplam 459 haberin 29 'unda (\% 6,3) başlık ile haber içeriği arasında uyum olmadığı belirlenmiştir. (Tablo 4) 
Kanser haberlerinin içeriği kanıta dayalı tıp açısından incelendiğinde kanıt durumu değerlendirilebilen toplam 455 haber içeriği mevcuttur. Bu 455 haber içeriğinden doğruluğu hakkında bilimsel kanıt bulunma oranı en yüksek olan içerikler "tanı" ile ilgili haber içerikleri olmuştur. Toplam 91 tanı ile ilgili haber içeriğinden 79'unun (\%86,82) doğruluğu yönünde bilimsel kanıt mevcuttur. Doğruluğu bilimsel kanıta dayanma oranı en düşük olan haber içerikleri ise "önlem ve korunma ile ilgili öneriler" veren haber içerikleridir. Önlem ve korunma ile ilgili önerilerden bahseden 145 haber içeriğinden yalnızca 82'sinin (\%56,56) doğruluğu yönünde bilimsel kanıt mevcuttur. (Tablo 5)

Kaynağ1 belirtilmemiş toplam 182 kanser haberinden, magazinsel haberler değerlendirme dışı bırakılıp 64 haber bilimsel kanıt yönünden incelendiğinde kaynağı belirtilmemiş kanser haberlerinin \% 54,68'i(n=35) ile ilgili veri tabanlarında kanıt bulunamamıştır. (Tablo 6)

\begin{tabular}{|l|c|c|}
\hline \multicolumn{3}{|l|}{ Tablo 1: Kanser Haberlerinin İçeriklerine Göre Dağılımı } \\
\hline & Sayı (n) & Yüzde (\%) \\
\hline Magazinsel & 220 & 25,88 \\
\hline Önlem ve korunma ile ilgili öneriler & 198 & 23,29 \\
\hline Tanı & 124 & 14,59 \\
\hline Etiyoloji & 118 & 13,88 \\
\hline Tedavi & 103 & 12,12 \\
\hline Kanser ile ilgili sayısal veriler & 64 & 7,53 \\
\hline Patofizyoloji & 23 & 2,71 \\
\hline Toplam* & 850 & 100 \\
\hline $\begin{array}{l}* \text { Bir haberde birden çok haber içeriği olabildiğinden, toplam haber içeriği } \\
\text { üzerinden hesaplanmışır }\end{array}$ & \multicolumn{2}{|c|}{} \\
\hline
\end{tabular}

Tablo 2: Kanser Haberlerinin Kanser Türlerine Göre Dağılımı

\begin{tabular}{|l|c|c|}
\hline & Sayı (n) & Yüzde(\%) \\
\hline Genel & 254 & 47,85 \\
\hline Meme kanseri & 38 & 7,18 \\
\hline Akciğer kanseri & 36 & 6,78 \\
\hline Kolon kanseri & 36 & 6,78 \\
\hline Jinekolojik kanserler & 34 & 6,40 \\
\hline Hematolojik maligniteler & 33 & 6,21 \\
\hline Prostat kanseri & 23 & 4,33 \\
\hline Baş - boyun kanserleri & 12 & 2,26 \\
\hline Mide kanseri & 11 & 2,07 \\
\hline Mesane kanseri & 9 & 1,69 \\
\hline Diğer * & 45 & 8,45 \\
\hline Toplam ${ }^{*}$ & 531 & 100 \\
\hline $\begin{array}{l}* \text { Diğer kanser türleri } \\
* * \text { Bir haberde birden çok kanser türü olabildiğinden, haberlerdeki toplam } \\
\text { kanser türü sayısı üzerinden hesaplanmiştır. }\end{array}$ \\
\hline
\end{tabular}

Tablo 3: Kaynak Belirtilen Kanser Haberlerinin Kaynak Kökenine Göre Dağılımı*

\begin{tabular}{|l|c|c|}
\hline & Sayı (n) & Yüzde(\%) \\
\hline Türk tıp doktoru & 151 & 47,78 \\
\hline Tıp dışı Türk kuruluşları & 59 & 18,68 \\
\hline Tıp kökenli Türk sağlık kuruluşu & 47 & 14,87 \\
\hline Diyetisyen & 24 & 7,59 \\
\hline Tip kökenli yabancı sağlık kuruluşu & 11 & 3,48 \\
\hline Tip dışı bilim insanı & 9 & 2,85 \\
\hline Tip dışı yabancı kurum & 7 & 2,22 \\
\hline Yabancı tıp doktoru & 4 & 1,27 \\
\hline Yabancı tıp dergisi & 2 & 0,63 \\
\hline Tip dişı yabancı bilim insanı & 2 & 0,63 \\
\hline Toplam* & 316 & 100 \\
\hline * Bir haberde birden fazla kaynak gösterilebildiği için, toplam kaynak \\
kökeni üzerinden hesaplanmıștır
\end{tabular}

Tablo 4 : Kanser Haberlerinde Haber Başlığı ile Haber İçeriğinin Uyum Durumu

\begin{tabular}{|l|c|c|}
\hline & Sayı (n) & Yüzde(\%) \\
\hline Uyumlu & 430 & 93,7 \\
\hline Uyumlu Değil & 29 & 6,3 \\
\hline Toplam & 459 & 100 \\
\hline
\end{tabular}




\begin{tabular}{|l|c|c|c|}
\hline \multicolumn{5}{|c|}{ Tablo 5: Kanser Haberlerinin İçeriğine Göre Kanıt Durumları } \\
\hline & $\begin{array}{c}\text { Kanıt var } \\
\mathrm{n}(\%)^{*}\end{array}$ & $\begin{array}{c}\text { Kanıt yok } \\
\mathrm{n}(\%)^{*}\end{array}$ & $\begin{array}{c}\text { Toplam } \\
\mathrm{n}(\%)^{*}\end{array}$ \\
\hline $\begin{array}{l}\text { Önlem ve } \\
\text { korunma ile } \\
\text { ilgili öneriler }\end{array}$ & $82(\% 56,56)$ & $63(\% 43,44)$ & $145(\% 100)$ \\
\hline Tanı & $79(\% 86,82)$ & $12(\% 13,18)$ & $91 \quad(\% 100)$ \\
\hline Etiyoloji & $66(\% 74,16)$ & $23(\% 25,84)$ & $89(\% 100)$ \\
\hline Tedavi & $49(\% 80,33)$ & $12(\% 19,67)$ & $61 \quad(\% 100)$ \\
\hline $\begin{array}{l}\text { Kanser ile } \\
\text { ilgili sayılsal } \\
\text { veriler }\end{array}$ & $40(\% 80,00)$ & $10(\% 20,00)$ & $50 \quad(\% 100)$ \\
\hline Patofizyoloji & $16(\% 84,21)$ & $3(\% 15,78)$ & $19 \quad(\% 100)$ \\
\hline Toplam & $332(\% 72,96)$ & $123(\% 27,03)$ & $455(\% 100)$ \\
\hline * Satır yüzdesi & & \\
\hline
\end{tabular}

\begin{tabular}{|c|c|c|}
\hline \multicolumn{3}{|c|}{$\begin{array}{l}\text { Tablo 6: Kaynak Belirtilmeyen Kanser Haberlerinin Kanıt } \\
\text { Durumu }\end{array}$} \\
\hline & Sayı (n) & Yüzde(\%) \\
\hline Kanit yok & 35 & 54,68 \\
\hline Kanit var & 29 & 45,32 \\
\hline Toplam & 64 & 100,0 \\
\hline
\end{tabular}

\section{Tartışma}

Kanser hakkında bilgi sahibi olmak, hastalığın erken tanısını, buna bağlı olarak da tedaviye yanıtı ve hayatta kalma süresini etkileyebilir. ${ }^{9}$ Toplumun, medyadan pasif biçimde kanser hastalıklarının belirtileri ve korunma yolları hakkında bilgi sahibi olup, bilinçlenmeleri konusunda medyanın gücü yadsınamaz. ${ }^{10}$ Kitle iletişim araçlarındaki kanser haberlerinin içerik ve kapsamının, halk sağlığının politikalarının şekillenmesindeki potansiyel etkisi de göz önüne alındığında kanser haberlerinin nasıl yansitıldığ 1 kanserin önlenmesi ve kontrolünde önem kazanmaktadır. ${ }^{11}$

Medya, erişimi kolay bir platform olması nedeniyle hastaları sağlık konularında bilgilendirebilecek önemli bir bilgi kaynağ1 olarak kabul edilir. Ama bu bilgilendirme içerikli haberler genelde tıbbi profesyonel kaynaklı haberlerden çok halkın ilgisini çekmeyi hedefleyen türdeki haberlerden oluşmaktadır. ${ }^{9}$ Beş gazetenin web sayfası ile beş haber sitesi dahil olmak üzere toplam on internet sitesinde, Kasım 2018-Aralık 2018 tarihleri arasındaki 1 aylık dönemde tekil (bağımsız) 459 kanser haberi üzerinden yapılan bu çalışmada, yapılan kanser haberlerinin içeriği açısından \%25,88 ile birinci sırada magazinsel haberler olduğu bulunmuştur. Cai ve arkadaşlarının 2000-2007 yılında önemli Çin gazetelerindeki kanser haberlerinin kapsam analizini yaptıkları çalışmalarında, 2007 yılında, 2003 yılına göre kanserin önlenmesi ve tedavisi ile ilgili haber sayılarında önemli bir artış olduğunu belirtmişlerdir. ${ }^{7}$ Yine Miyawaki ve arkadaşlarının yaptıkları benzer bir çalışmada içerik açısından ilk sırada \%34,5 ile kanserin tedavisi ile ilgili haberler olduğu görülmüştür. ${ }^{12}$ Ülkemizdeki kanser haberlerinin daha çok magazinsel özellikte olması okuyucuların daha fazla ilgisini çekecek yöndeki haberlerin yayınlanmasının hedefleniyor olmasından kaynaklanabilir.

Türkiye'de 2015 TUİK verilerine göre en sık teşhis edilen ilk 4 kanser türü kadınlarda meme, tiroid, kolorektal, uterus korpus kanserleri iken; erkeklerde akciğer, prostat, kolorektal, mesane kanserleridir. Bu çalışmada da kanser türlerinin belirtildiği haberlerin \%13,72'sini "Sağlık Bakanlığı 2015 Türkiye Kanser İstatistikleri” verileri ile uyumlu olarak meme kanseri haberleri oluşturmaktadır. Slater ve arkadaşlarının gazetelerdeki kanser haberlerini incelediği çalışmasında, meme kanseri en sık işlenen konu olarak 1.sırayı almıştır. ${ }^{11}$ Birleşik Krallıkta 2011-2012 yılları arasında gerçekleştirilen ve en sık görülen ilk dört kanser türünü içeren, 9178 medya haber makalesinin incelendiği bir çalışmada 2011 yılında \%22,90 ve 2012 yılında \%19,60 ile ilk sırada meme kanseri makalelerinin yer aldığı görülmüştür. ${ }^{12}$ Kanada'da 2000 yllındaki yerel ve ulusal gazetelerdeki kanser haberlerinin kapsamının araştırıldı ğ 1 bir başka çalışmada, incelenen 748 kanser makalesi içinde 1 . sirada \% 20,59'luk bir oranla meme kanseri haberleri olduğu tespit edilmiştir. ${ }^{13}$ Hurley ve arkadaşlarının ABD'de gazetelerdeki kanser haberlerinin kapsamını inceledikleri çalışmada da bizim sonuçlarımıza benzer şekilde ilk sırada meme kanseri haberlerinin yer aldığı görülmüştür. ${ }^{14}$ İngiltere'de Ocak-Aralık 2009 döneminde en sık görülen ilk 10 kanserin gazete haberlerinin taramasıyla tespit edildiği bir başka çalışmada, ilk sırada bulunan türün; 5832 haberin 
\%10.48'ni oluşturan meme kanseri olduğu görülmüştür. ${ }^{9}$

2015 verilerine göre erkeklerde en sık, kadınlarda beşinci sıklıkta görülen akciğer kanseri, yapılan bu çalışmada da tanısı belirtilen 277 kanser haberi içinde \% 13,00 ile ikinci sırada yer almaktadır. 2011-2012 yılları arasındaki medya haber makalelerinin incelendiği Birleşik Krallık çalışmasında da bu çalışmanın sonuçları ile benzer şekilde, 2012 yılının kanser haberleri içersinde \% 9,40 ile ikinci sırada akciğer kanseri haberleri yer almıştır. ${ }^{12}$

2015 verilerine göre Türkiye’de erkeklerde ikinci sırada en çok görülen kanser prostat kanseri olmasına rağmen bu çalışmada, prostat kanserinin, türü belirtilmiş kanser haberleri arasında 6. sırada olduğu görülmüştür. Bu durum, haberi hazırlayanların sağlık konusunda kadın okuyucuların daha ilgili olduğunu düşünmeleriyle ya da ülkemizdeki kanser görülme sıklıklarına ellerindeki istatistikler doğrultusunda yaklaşmış olmalarıyla ilgili olabilir.

Medyada yapılan ünlülerin kanser haberleri, bazı kanser türlerine olan farkındalığı artırmada da etkili olmaktadır. Avusturalyalı ünlü şarkıcı Kylie Minouge’a meme kanseri teşhisinin konulması ve bu konunun basında geniş yer alması, Avusturalya'da meme kanseri tarama programlarında artışa yol açmış ve bu; "Kylie etkisi” olarak adlandırılmıştır. ${ }^{16} \mathrm{Bu}$ çalışmada bulunan, halkın daha çok ilgisini çektiği düşüncesiyle yapılan ve kanser haberi içeriği açısından ilk sırada yer alan magazinsel haberlerde yer verilen ünlülerin kanser haberleri de bu bağlamda kanser fakındalığını artırmada yararlı olabilir.

Çalışmamızın sonuçlarına göre özellikle kaynağı belirtilmemiş olan kanser haberlerinde daha çok olmak üzere haber içeriklerinin herhangi bir bilimsel kanıtlarının olmayabileceği de tespit edilmiştir. Medya veya diğer kitlesel haber araçlarıyla kişilerin dikkatini çekecek haberler yapmak bir habercilik yöntemi olmasına rağmen, yapılan haberin doğruluğunun araştırılması ve özellikle bilimsel verilerle uyumlu bilgi taşıyor olmaları çok önemli bir konudur. Sağlık hizmet sunucuları ve medya iş birliği ile, kanser konusunda halkı doğru bilgilendirmek, bilimsel değeri olan haberlerle halkın karşısına çıkmak, halkın bilinçlenmesi ve bu konuda doğru hareket edebilmesi açısından önemlidir. Bu bağlamda haberi yapan gazetecilerin, haberi hazırlama aşamasında alanında uzman kişilerden görüş almaları, halka güncel ve doğru mesajları iletmeleri açısından önemlidir.

\section{Sonuç}

Sağlık eğitimi, hastalıklardan korunmada sağlık hizmeti sunanların sahip olduğu en etkili ve en ucuz enstrümandır. Türkiye gibi tedavi hizmetlerinin öne çıkarıldığı, birincil korunmaya yeterli kaynak tahsisinin yapılmadığı ülkelerde medyanın kanser veya diğer sağlık konularında ücretsiz tanıtım aracı olarak kullanılması akılcı bir yaklaşım olabilir. Bu amaçla internet medyasına yönelik bazı yasal düzenlemeler yapılarak kanser haberlerinin yayınlanma sıklığı ve içerik standartları belirlenebilir.

Doğru ve güvenilir bilgileri içeren haberlerin yapılmasında, uzmanlar ve gazeteciler iş birliği içinde olmak durumundadırlar. Böylece toplumun hem kanser konusundaki fakındalığı hem de doğru bilgilendilmesi sağlanmış olur.

Sağlık Bakanlığı ve halk sağlığını ilgilendiren diğer tüm kuruluşlar, kamu bilgilendirme kampanyaları tarzında gazetelerde yayımlanmak üzere makaleler hazırlamalıdırlar. Bu sayede insanlar hangi semptomların varlığında aile hekimlerine gitmeleri konusunda bilgi sahibi olabilirler. Sonuçta, kanserde sağ kalım oranlarını daha yüksek düzeylere çıkarma fırsatı yakalanabilir. 
Sakarya Tip Dergisi 2019;9(4):619-625

MURATDAĞI ve Ark., Medyada Yer Alan Kanser Haberlerinin Değerlendirilmesi

Kaynaklar

1. Donelle L, Hoffman-Goetz L, Clarke JN. Ethnicity, genetics, and breast cancer: media portrayal of disease identities. Ethn Health 2005;10:185-97.

2. DeFleur ML, Davenport L, Cronin M, DeFleur M. Audience recall of news stories presented by newspaper, computer, television and radio. Journalism Q 1992;69:1010-22.

3. McDonnell DD, Lee HJ, Kim YB, Kazinets G, Moskowitz JM (2008). Cancer coverage in a mainstream and Korean American online newspaper: lessons for community intervention. Patient Educ Couns 71(3):388-395 doi:10.1016/j.pec.2008.03.004

4. Milazzo S, Ernst E (2006) Newspaper coverage of complementary and alternative therapies for cancer-UK 2002-2004. Support Care Cancer 14(9):885-889 doi:10.1007/s00520-006$0068-z$

5. http://www.tuik.gov.tr/PdfGetir.do?id=27620 Erişim Tarihi : 8 Mayıs 2019

6. https://hsgm.saglik.gov.tr/depo/birimler/kanser db/istatistik/Turkiye_Kanser_Istatistikleri 2015.pdf Erisim Tarihi: 8 Mayıs 2019

7. Jianping Cai, Lida Yang, Zhenhong Liu, Zhiyong Ma, Yu Liu. Comprehensive analysis of cancer coverage in important. Support Care Cancer 2009;17:329-332 DOI 10.1007/s00520008-0494-1

8. Phillips DP, Kanter EJ, Bednarczyk B, Tastad PL. Importance of the lay press in the transmission of medical knowledge to the scientific community. N Engl J Med 1991;325:1180-1183

9. Williamson JML, Jones $I H$, Hocken DB. How does the media profile of cancer compare with prevalence? Ann R Coll Surg Engl 2011; 93: 9-12
10. Moriarty CM, Stryker CE. Prevention and screening efficacy messages in newspaper accounts of cancer. Health Education Research 2008;23(3): 487-498

11. Slater MD ,Long M, Bettinghaus EP, Reineke JB. News Coverage of Cancer in the United States: A National Sample of Newspapers, Television, and Magazines. Journal of Health Communication 2008; 13:523-537

12. Konfortion J, Jack RH, Davies EA. Coverage of common cancer types in UK national newspapers: a content analysis. BMJ Open 2014;4:e004677. doi:10.1136/bmjopen-2013-004677

13. Hoffman-Goetz L, PhD, Friedman DB. Disparities In The Coverage Of Cancer Information In Ethnic Minority And Mainstream Mass Print Media. Ethnicitye Disease 2005; 15(2):332-40

14. Hurley RJ, Riles JM, Sangalang A. Online Cancer News: Trends Regarding Article Types, Specific Cancers, and the Cancer Continuum. Health Communication 2014; 29:41-50.

15. Miyawakia R, Shibatab A, Ishiia K, and Okaa K. News Coverage of Cancer in Japanese Newspapers: A Content Analysis, HEALTH COMMUNICATION 2017, VOL. 32, NO. 4, 420-426 http://dx.doi.org/10.1080/10410236.2016.1138391

16. Chapman S, McLeod K, Wakefield M and Holding S. Impact of news of celebrity illness on breast cancer screening: Kylie Minogue's breast cancer diagnosis, The Med J Aust 2005; 183 (5): 247-250. || doi: 10.5694/j.1326-5377.2005.tb07029.x, 